\title{
The Risk of Night Shift Workers to the Glucose Blood Levels, Saliva, and Dental Caries
}

\author{
Retno Indrawati Roestamadji ${ }^{1}$ \\ Anis Irmawati ${ }^{1, \oplus}$ \\ ${ }^{1}$ Department of Oral Biology, Faculty of Dental Medicine, \\ Universitas Airlangga, Surabaya, Indonesia \\ 2Doctor of Dental Surgery Student, Faculty of Dental Medicine, \\ Universitas Airlangga, Surabaya, Indonesia \\ ${ }^{3}$ Department of Oral Medicine, Faculty of Dental Medicine, \\ Universitas Airlangga, Surabaya, Indonesia
}

\begin{abstract}
Address for correspondence Anis Irmawati, M. Kes, Department of Oral Medicine, Faculty of Dental Medicine, Universitas Airlangga, Surabaya 60132, Indonesia (e-mail: anis-m@fkg.unair.ac.id).
\end{abstract}

\begin{abstract}
Abastract
Keywords

- circadian rhythm

- blood glucose

- dental caries

- saliva

- night shift worker

Objective This study aimed to provide the correlation of circadian rhythms of night shift workers with blood glucose levels, saliva, and dental caries.

Materials and Methods This study was conducted on night shift and nonshift workers to measure fasting blood glucose (FBG), 2-hour postprandial blood glucose (2-PP $\mathrm{BG}$ ), saliva flow rate, $\mathrm{pH}$ saliva, and caries with the decay-missing-filled total (DMF-T) index. Data analysis was done using independent $t$-test and correlation test with Pearson correlation.

Results There were significant differences in night shift and nonshift workers in FBG $(p=0.000), 2$-PP BG $(p=0.000)$, flow rate saliva $(p=0.000)$, and DMF-T index $(p=0.001)$. Correlation test showed positive correlation between FBG and $\mathrm{pH}$ saliva $(r=0.42, p=0.029)$ and DMF-T index $(r=0.521, p=0.005)$ of night shift workers. The 2-PP BG also showed positive correlation with $\mathrm{pH}$ saliva $(r=0.493, p=0.009)$ and DMF-T index $(r=0.743, p=0.000)$. The DMF-T index showed negative correlation with flow rate saliva $(r=-0.398, p=0.04)$. In the nonshift workers, correlation test showed a correlation between FBG and DMF-T index $(r=0.384, p=0.048)$. The DMF-T index showed correlation with flow rate saliva $(r=0.6, p=0.001)$.

Conclusion There is a circadian rhythm correlation between night shift workers to blood glucose levels, flow rate saliva, $\mathrm{pH}$ saliva, and dental caries.
\end{abstract}

\section{Introduction}

In the era of globalization, the needs of humans keep getting increased. The development of technology encourages people to explore their potential to fulfill their needs, both physically and psychologically, by working. Shift working is a human resource management in the working system to maximize work productivity and to complete the customer's needs. ${ }^{1}$ Currently, the shift working system has been applied in various industrial, manufacturing, and service sectors. In industrialized countries, more than $20 \%$ of the population works in the shifts. As many as 15 to $25 \%$ of workers in the world work in the shift system. ${ }^{2}$

Regulation of human body metabolism is influenced by a system known as circadian rhythm. Circadian rhythm is the daily oscillations of biological processes, which is influenced by the body's biological clock. The circadian rhythm is centrally controlled by the suprachiasmatic nucleus, located in the hypothalamus, which is linked to the dark-light cycle and transmits information to peripheral organs including peripheral cycles to modulate the waking up-sleeping rhythms every 
day and other organ functions. The circadian system has a role in regulating tissue metabolism and hormonal secretions. ${ }^{3}$

Night shift workers experience schedule changes differently from usual people with regard to mealtime, temperature, exercise, or other environmental factors and is known as zeitgeber. ${ }^{4}$ The synchronization between the circadian system and zeitgebers of night shift workers can cause circadian misalignment, which is detrimental to their health. ${ }^{5}$ The night shift workers are known to have a bad effect on their general health, which is associated with several diseases related to lifestyle. A study reports that night shift workers have more systemic diseases, one of these is type 2 diabetes mellitus. ${ }^{6}$ Diabetes mellitus is a disease characterized by high blood glucose levels, caused by an increase in cellular resistance to insulin performance, leading to various metabolic disorders. ${ }^{7}$ Diabetes mellitus is a metabolic disease that often occurs in Indonesia. The prevalence of diabetes mellitus in Indonesia by the year 2007 was 5.7\% and by the year 2013 was $6.9 \%{ }^{8}$ The night shift workers with type 2 diabetes mellitus have differences in pancreatic $\beta$ cell response, glucose and lipid metabolism, and increased risk of developing syndrome metabolic. Sleeping time changes in night shift workers cause impaired glucose tolerance and reduced insulin response. ${ }^{8}$

Diabetes mellitus is a predisposing factor for caries. Caries prevalence in Indonesia increased from 43.4\% in 2007 to $53.2 \%$ in $2013 .{ }^{9,10}$ Caries can occur in patients with poorly controlled diabetes mellitus, because carbohydrate fermentation in the saliva increases, causing increased acid production that promotes caries. In patients with diabetes, the state of saliva also changes, such as flow rate and $\mathrm{pH}$ saliva. Patients with type 2 diabetes mellitus experience polyuria that causes intensive fluid loss, reduction in response to infection, disorders of connective tissue metabolism, and various microvascular changes that can cause dental caries. ${ }^{7,11}$

Management of circadian rhythms has been studied previously using melatonin therapy. Existing melatonin therapy is used to improve sleep quality in night shift workers. ${ }^{12}$ However, there has been no previous study of the circadian rhythms related to the risk of diabetes mellitus and the risk of dental caries in night shift workers.

\section{Aims or Objective}

The aim of this study was to determine the correlation between circadian rhythm of night shift workers and the risk of diabetes mellitus and caries risk. Flow rate saliva, $\mathrm{pH}$ saliva, and decay-missing-filed total (DMF-T) index were analyzed to describe the risk of caries. The fasting blood glucose (FBG) and 2-hour postprandial blood glucose (2-PP FB) were used to describe the risk of diabetes mellitus.

\section{Materials and Methods}

The type of research in this study was observational analytic with a cross-sectional design. Ethical approval was obtained from the Ethics and Law Committee of Universitas Airlangga Hospital, Surabaya (185/KEH/2018).

\section{Research Subjects}

The subjects of this study were night shift and nonshift workers, males, aged 25 to 40 years, worked at least 1 year at Universitas Airlangga Hospital and other hospitals in Surabaya. The research subjects were 27 nightshift workers as exposed and 27 nonshift groups as control. All data were summarized as age, body weight, and height.

\section{Blood Glucose Measurement}

Fasting blood glucose and 2-PP BG measurements were performed using glucometer (Accu-Chek; Roche Diabetes Care Inc., United States). On FBG examination, the subjects were asked to fast 8 hours (not allowed to eat and drink except drinking water) before blood glucose examination. Then, after 8 hours, an FBG examination was performed with glucometer. Criteria for FBG for diabetes mellitus are fasting $\geq$ $126 \mathrm{mg} / \mathrm{dL}$. 2-PP BG examination was performed after FBG measurement. Subjects were allowed to eat and drink, and after 2 hours 2-PP BG examination was performed. Blood glucose criteria of 2-PP for diabetes mellitus are $\geq 200 \mathrm{mg} / \mathrm{dL}$.

\section{Flow and pH Saliva Measurement}

Saliva samples were collected for measuring salivary $\mathrm{pH}$ using a pH strip-meter (Whatman; PH1170-11A; GE Healthcare). Saliva samples were collected from each participant in the morning between 9 and 11 am using passive drool methods. For the collection of these samples, all participants were requested to be as quiet as possible. They were instructed to allow the saliva to flow into the mouth as normally as possible and expectorate into the large test tubes provided. In all, $6 \mathrm{~mL}$ of sample was collected from each participant. The $\mathrm{pH}$ of each sample was determined within the first half an hour after collection. ${ }^{13}$

\section{DMF-T Index Examination}

DMF-T index examination was performed using a dental explorer and dental mirror, followed by examining of decayed teeth due to caries (decay), missing/removed teeth due to caries (missing), teeth that were patched or filled with caries and were filled were examined. Calculation of DMF-T index was done by the formula:

$$
D M F-T \frac{D+M+F}{\text { number of subject }}
$$

with criteria:

1. $0-1.1=$ very low

2. $2-26=$ low

3. $7-4.4=$ moderate

4. $5-6.5=$ high

5. > = very high

\section{Statistical Analysis}

The data were analyzed statistically using SPSS 19. Independent $t$-test was used for analysis between two groups. Pearson correlation was used for correlation analysis between the two groups. 


\section{Results}

Fifty-four subjects in this research were males: 27 as night shift workers and 27 as nonshift workers. Night shift workers had an average age of $32.26 \pm 4.53$ years and nonshift workers had an average age of $33.08 \pm 5.09$ years. There were no age differences between night shift worker and nonshift workers $(p=0.537)$. Night shift workers also had a significantly higher body weight than nonshift workers $(p=0.000)$. There were no differences in the body height showed no differences, but the body mass index (BMI) showed a significant difference $(p=$ 0.000 ). Both groups had experience of working for more than 5 years ( 48.1 and $44.4 \%$, respectively). The highest frequency of working in the night shift workers was thrice a week (44.5\%), followed by once a week (33.3\%) and once a month (22.2\%) (-Table 1).

The night shift workers had higher FBG $(121.56 \pm 31.82$ $\mathrm{mg} / \mathrm{dL})$ and 2-PP BG $(91.22 \pm 13.25 \mathrm{mg} / \mathrm{dL})$ than FBG (163.06 $\pm 60.44 \mathrm{mg} / \mathrm{dL})$ and $2-\mathrm{PP} \mathrm{BG}(98.67 \pm 19.8 \mathrm{mg} / \mathrm{dL})$ in nonshift workers $(p=0.000)$ ( - Table 2 ).

The mean flow rate of saliva was found to be significantly lower in the night shift workers than that in nonshift workers $(p=0.000)$. The night shift workers had high DMF-T index and nonshift workers had moderate DMF-T index ( $p=0.000$ ). The saliva $\mathrm{pH}$ showed no differences between night shift workers and non-night shift workers $(p=0.710)$ (-Table 3 ).

In the correlation analysis, there was a significantly positive correlation of FBG and 2-PP BG to saliva $\mathrm{pH}$ and DMF-T index in night shift workers (-Table 4). There was a negative correlation between DMF-T index and saliva flow rate $(p=0.04 ; r=-0.398)$ (-Table 5).

In nonshift workers, there was only a significantly positive correlation of FBG with DMF-T index ( $p=0.048 ; r=0.384$ ) (-Table 6). The DMF-T index had a positive correlation with saliva flow rate $(p=0.001 ; r=0.6)(-$ Table 7$)$.

\section{Discussion}

This is the first study to analyze the circadian rhythms related to the risk of diabetes mellitus and the risk of dental caries in night shift workers. This study was conducted on night shift and nonshift workers at Universitas Airlangga Hospital. Surabaya is one of the biggest cities in Indonesia, which is a tropical country. Tropical populations generally work from morning to evening and sleep at night. Night shift workers

Table 1 Demographic of all subjects

\begin{tabular}{|c|c|c|c|}
\hline Variables & $\begin{array}{l}\text { Night shift worker } \\
(n=27) \\
\text { Mean } \pm \text { SD }\end{array}$ & $\begin{array}{l}\text { Nonshift worker } \\
(n=27) \\
\text { Mean } \pm \text { SD }\end{array}$ & $p$-Value \\
\hline Sex & Male & Male & - \\
\hline Ages (years) & $32.26 \pm 4.53$ & $33.08 \pm 5.09$ & 0.537 \\
\hline Body weight (kg) & $84.00 \pm 10.03$ & $53.93 \pm 6.87$ & $0.000^{\mathrm{a}}$ \\
\hline Body height $(\mathrm{cm})$ & $168 \pm 6.29$ & $167.37 \pm 5.79$ & 0.531 \\
\hline BMI & $29.52 \pm 1.89$ & $19.17 \pm 1.32$ & $0.000^{\mathrm{a}}$ \\
\hline \multicolumn{4}{|c|}{ Lifetime of working } \\
\hline$<1 \mathrm{y}$ & $4(14.8 \%)$ & $5(18.5 \%)$ & \\
\hline $1-5 y$ & $10(37 \%)$ & $10(37 \%)$ & \\
\hline$>5 y$ & $13(48.1 \%)$ & $12(44.4 \%)$ & \\
\hline \multicolumn{4}{|c|}{ Lifetime for night shift } \\
\hline 3 times a wk & $12(44.5 \%)$ & & \\
\hline 1 time a wk & $9(33.3 \%)$ & & \\
\hline 1 time a mo & $6(22.2 \%)$ & & \\
\hline
\end{tabular}

Abbreviations: BMI, body mass index; SD, standard deviation.

aResults of independent $t$-test in the comparison between the case and the control groups, significant at $p<0.05$

Table 2 FBG and 2-PP BG value in both groups

\begin{tabular}{|l|l|l|l|}
\hline Variables & $\begin{array}{l}\text { Night shift worker } \\
(\boldsymbol{n}=27) \\
\text { Mean } \pm \text { SD }\end{array}$ & $\begin{array}{l}\text { Nonshift worker } \\
(\boldsymbol{n}=27) \\
\text { Mean } \pm \text { SD }\end{array}$ & $p$-Value \\
\hline FBG $(\mathrm{mg} / \mathrm{dL})$ & $121.56 \pm 31.82$ & $91.22 \pm 13.25$ & $0.000^{\mathrm{a}}$ \\
\hline 2 -PP BG $(\mathrm{mg} / \mathrm{dL})$ & $163.06 \pm 60.44$ & $98.67 \pm 19.8$ & $0.000^{\mathrm{a}}$ \\
\hline
\end{tabular}

Abbreviations: FBG, fasting blood glucose; 2-PP BG, 2 postprandial blood glucose; SD, standard deviation.

aResults of independent $t$-test in the comparison between the case and the control groups, significant at $p<0.05$. 
Table 3 Flow rate saliva, pH saliva, and DMF-T index in all groups

\begin{tabular}{|l|l|l|l|}
\hline Variables & $\begin{array}{l}\text { Night shift worker } \\
(\boldsymbol{n}=27) \\
\text { Mean } \pm \text { SD }\end{array}$ & $\begin{array}{l}\text { Nonshift worker } \\
(\boldsymbol{n}=27) \\
\text { Mean } \pm \text { SD }\end{array}$ & $p$-Value \\
\hline Flow rate saliva $(\mathrm{mL} / \mathrm{min})$ & $0.24 \pm 0.15$ & $0.57 \pm 0.27$ & $0.000^{\mathrm{a}}$ \\
\hline pH saliva & $5.89 \pm 1.48$ & $5.74 \pm 1.43$ & 0.710 \\
\hline DMF-T & $9.74 \pm 5.07$ & $3.52 \pm 2.46$ & $0.001^{\mathrm{a}}$ \\
\hline
\end{tabular}

Abbreviations: DMF-T, decay-missing-filling total; SD, standard deviation.

aResults of independent $t$-test in the comparison between the case and the control groups, significant at $p<0.05$.

Table 4 Correlation between FBG and 2-PP BG to flow rate saliva, pH saliva, and DMF-T in night shift workers

\begin{tabular}{|l|l|l|l|l|}
\hline \multirow{2}{*}{ FBG } & & Flow rate saliva & pH saliva & DMF-T \\
\hline \multirow{2}{*}{ 2-PP BG } & Person correlation & 0.109 & $0.420^{\text {a }}$ & $0.521^{\text {b }}$ \\
\cline { 2 - 5 } & P & 0.588 & 0.029 & 0.005 \\
\hline & Person correlation & 0.020 & $0.493^{\text {b }}$ & $0.743^{\text {b }}$ \\
\cline { 2 - 5 } & $p$-Value & 0.922 & 0.009 & 0.000 \\
\hline
\end{tabular}

Abbreviations: DMF-T, decay-missing-filling total; FBG, fasting blood glucose; 2-PP BG, 2 postprandial blood glucose.

${ }^{a}$ Correlation is significant at the level 0.05 .

${ }^{\mathrm{b} C}$ Correlation is significant at the level 0.01

Table 5 Correlation between flow rate saliva to $\mathrm{pH}$ saliva and DMF-T in night shift workers

\begin{tabular}{|l|l|l|}
\hline Flow rate saliva & pH saliva & DMF-T \\
\hline $\begin{array}{l}\text { Person } \\
\text { correlation }\end{array}$ & 0.205 & $-0.398^{\mathrm{a}}$ \\
\hline$p$-Value & 0.306 & 0.04 \\
\hline
\end{tabular}

Abbreviation: DMF-T, decay-missing-filling total.

${ }^{a}$ Correlation is significant at the level 0.05 .
Table 7 Correlation between flow rate saliva to $\mathrm{pH}$ saliva and DMF-T in nonshift workers

\begin{tabular}{|l|l|l|}
\hline Flow rate saliva & pH saliva & DMF-T \\
\hline $\begin{array}{l}\text { Person } \\
\text { correlation }\end{array}$ & 0.182 & $0.6^{\mathrm{a}}$ \\
\hline$p$-Value & 0.364 & 0.001 \\
\hline
\end{tabular}

Abbreviation: DMF-T, decay-missing-filling total.

${ }^{a}$ Correlation is significant at the level 0.01 .

Table 6 Correlation between FBG and 2-PP BG to flow rate saliva, pH saliva, and DMF-T in nonshift workers

\begin{tabular}{|l|l|l|l|l|}
\hline \multirow{2}{*}{ FBG } & & Flow rate saliva & pH saliva & DMF-T \\
\hline \multirow{2}{*}{ 2-PP BG } & Person correlation & 0.334 & 0.286 & $0.384^{\text {a }}$ \\
\cline { 2 - 5 } & $\mathrm{P}$ & 0.89 & 0.147 & 0.048 \\
\hline & Person correlation & 0.243 & 0.197 & 0.371 \\
\cline { 2 - 5 } & $p$-Value & 0.222 & 0.324 & 0.57 \\
\hline
\end{tabular}

Abbreviations: DMF-T, decay-missing-filling total; FBG, fasting blood glucose; 2-PP BG, 2 postprandial blood glucose.

${ }^{a}$ Correlation is significant at the level 0.05 .

work in the opposite of the usual conditions, which fight the normal circadian rhythm. ${ }^{14}$ When these workers are awake at night, they receive light by the retina. Furthermore, it is forwarded by the retinal hypothalamic tract to the suprachiasmatic nucleus located in the hypothalamus. The light signal is forwarded to the spinal cord and the superior cervical ganglion toward the pineal gland. The pineal gland receives a light signal, so it does not release norepinephrine to pinealocyte. ${ }^{15}$ Then $\beta$-adrenergic receptors are not activated so that there is a decrease in melatonin secretion..$^{16}$ The decrease in melatonin secretion causes a decrease in antioxidants resulting more production of reactive oxygen species (ROS), ${ }^{17}$ which is in body fluids and saliva. Increased ROS forms oxidative stress that is followed by an increase in malondialdehyde
(MDA), which continues to create imbalance in the body and affect disease progression. ${ }^{18-20}$ Increased blood glucose can be affected by insulin, which experiences resistance that is influenced by levels of ROS, namely excessive MDA in the cell. Free radicals (MDA) are formed disproportionately by oxidation of nonenzymatic proteins and oxidative degradation of glycated proteins (advanced glycation end products) in type 2 diabetes mellitus. ${ }^{21}$

In physiological conditions, pancreatic $\beta$ cells produce insulin in normal amounts that can transport glucose from the blood into the cell. However, in night shift workers with insulin resistance receptors, insulin receptors are not sensitive leading to increased levels of blood glucose. ${ }^{22}$ Chronic increase in the blood glucose levels can increase the risk of 
type 2 diabetes mellitus. ${ }^{23}$ In a previous study, it was found that when subjects ate and slept at odd hours, plasma blood glucose increased despite increasing in the dose of insulin. This is caused by circadian misalignment that causes a disruption of the glucose/insulin regulation system in the body. ${ }^{24}$

In this study, there were significant differences between FBG and 2-PP BG of night shift and nonshift workers. Night shift workers had significantly higher blood glucose (FBG=121.56 $\pm 31.82 \mathrm{mg} / \mathrm{dL}$ and 2-PP BG=163.06 \pm 60.44 $\mathrm{mg} / \mathrm{dL}$ ) compared with nonshift workers (FBG $=91.22 \pm 13.25$ $\mathrm{mg} / \mathrm{dL}$ and 2 -PP BG=98.67 $\pm 19.8 \mathrm{mg} / \mathrm{dL}$ ). This shows that night shift workers are more at risk of developing diabetes mellitus than nonshift workers. In type 2 diabetes mellitus, there is insulin resistance or decreased insulin secretion that causes hyperglycemic conditions, ${ }^{25,26}$ increases plasma osmolarity caused by cell osmosis to high blood glucose levels. The body compensates for the presence of glucose from the blood leading to the kidneys which causes increased kidney filtration, so more urine is produced (polyuria). Polyuria causes dehydration in the body and the oral cavity becomes dry, causing a decrease in salivary flow. In this research, the flow rate of saliva is different between night shift workers and nonshift $(p=0.000)$ workers. In the night shift workers, the flow rate is lower than nonshift workers. The lower flow rate of saliva causes $\mathrm{pH}$ imbalance, and then causes the oral cavity to become more acidic so that the salivary $\mathrm{pH}$ decreases. But, the result of this study showed no difference in $\mathrm{pH}$ saliva between night shift worker and nonshift worker $(p=0.710)$.

The FBG and 2-PP BG in the night shift worker are different compared with that in nonnight shift worker. One of the factors related to this condition is the duration of working and especially duration of working during night. Most of subjects in this research has lifetime of working more than 5 years (48.1\%) and lifetime of night working with higher frequency is three times a week (12 times a month) (44.5\%). This condition can support the emergence of hyperglycemia that leads to diabetes. This result is similar to the study by Vetter et al who explain that work schedules including night shifts for 10 years had a significantly higher type 2 diabetes likelihood than those who never worked in night shifts. Working for more than eight night shifts per month had a significant $36 \%$ higher likelihood of type 2 diabetes compared with who never worked in night shifts. ${ }^{27}$

A decrease in saliva pH causes an acidic condition in the oral cavity. The aciduric and acidogenic bacteria that develop in an acidic condition, namely Streptococcus mutans, increase in the oral cavity. Streptococcus mutans colonize to form biofilms in the teeth which then form plaques. In the early stages, caries can form a white lesion called the white spot. The organic acids produced by caries bacteria diffuse in the enamel and dentine resulting in increased demineralization and decreased remineralization. ${ }^{28}$ The process occurs continuously in later periods. Night shift workers have glucose intake at night ${ }^{29}$ that is not balanced with maintaining oral hygiene by brushing their teeth or gargling properly that affect the progression of cavity formation and lead to dental caries. The dental caries is one of the indicators in DMF-T index. There is DMF-T difference between night shift workers and nonshift workers $(p=0.001)$. The night shift workers have very high DMF-T index and non-night shift workers have moderate DMF-T index. In a previous study, it was found that night shift workers had the possibility of having untreated teeth and thus decreased oral health status. Health behaviors in brushing teeth twice a day can also affect this aspect. ${ }^{30}$ Based on previous study, 20 people who woke up at night were less likely to brush their teeth than someone who woke up in the morning, increasing the risk of dental caries in night shift workers.

The night shift working has some clinical consequences like higher incidence of obesity and diabetes. The oral status is also affected. Shift workers had a $27 \%$ greater possibility of having periodontitis than daytime workers. ${ }^{31}$ The other effect shift workers may face is dental caries. There is a positive correlation between FBG and 2-PP BG with pH saliva and DMF-T index as caries status in night shift workers. The risk of increasing caries in night shift workers is indicated by a decrease in salivary flow rate $(r=-0.398, p=0.04)$. The risk of increased caries is also supported by an increase in FBG level $(r=0.521, p=0.005)$ and 2-PP BG $(r=0.743, p=0.000)$. Dental caries in night shift workers can be caused by a decrease in threshold value of sweet taste, causing decreased sensitivity to sweetness, especially a decrease in sensitivity to the papilla fungiform. ${ }^{32}$ Decreased sensitivity to sweetness causes the night shift workers to not feel the sweet taste, leading to increased glucose consumption..$^{33}$ Excessive increase in glucose consumption triggers dental caries. Significant decrease in the salivary flow rate was found in hyperglycemia status as in both type of diabetes. Among the several reasons that contribute to the decreased salivary flow rate in diabetes, lies the fact that following the hyperglycemia and glucosuria, body fluids are more excreted, and subsequently, secretion of saliva is reduced. ${ }^{34}$

The DMF-T index in this research found different base on blood glucose status in night shift and nonnight shift workers. The higher DMF-T index in night shift worker has positive correlation with FBG $(r=0.005, p=0.521)$ and 2-PP $\mathrm{BG}(r=0.743, p=0.000)$. The other factor that influences the higher DMF-T index is flow rate of saliva. There is a negative correlation between flow rate of saliva and DMF-T index $(r=-0.398, r=0.04)$. This result is similar with that reported by Seethalakshmi et al (DMF-T index was higher in the diabetic group). ${ }^{35}$ This is due to loss of protective mechanism of the saliva in diabetics. The cleansing and buffering action of saliva are also impaired. Low salivary $\mathrm{pH}$ promotes the growth of aciduric bacteria that then allows the acidogenic bacteria to proliferate creating an inhospitable environment for the protective oral bacteria. This allows for a shift in the oral environmental balance to favor cariogenic bacteria, which further lowers the salivary $\mathrm{pH}$ and the cycle continues. ${ }^{36} \mathrm{pH}$ saliva, flow rate of saliva, and calcium have protecting roles in dental caries. pH saliva is itself determined by bicarbonate, phosphate, and protein, which play an important role as a buffer. ${ }^{37}$ Calcium has solubility that affected development and reservoir of tooth decayed. The amount of calcium in tooth decayed not only from tooth but also from 
exchanged process with calcium saliva that surrounds teeth. The diabetic condition showed low levels of calcium. ${ }^{11}$ Another factor that stimulates the caries in diabetic patient is high glucose concentration in saliva. Highest glucose concentration in saliva affected the presence of Streptococcus mutans and Lactobacillus, which play important role in caries. ${ }^{37}$

In the present study, there was significant correlation $(p=0.04)$ between the flow rate of saliva and DMF-T index in night shift worker. But the DMF-T index and $\mathrm{pH}$ saliva are influenced by blood glucose status $(p<0.05)$. The hyperglycemia condition as diabetes mellitus patients, they had significant decrease in flow rate saliva and causes the lower $\mathrm{pH}$ saliva. But this condition was not found in this research. The lower $\mathrm{pH}$ saliva is not correlated with the reduced flow rate of saliva ( $p=0.306$ ). This could be caused by increased fluid intake by diabetics due to polydipsia. Because buffering capacity is dependent on the $\mathrm{pH}$ levels, diabetic condition had salivary buffering capacity correlating with the $\mathrm{pH}$ saliva. ${ }^{38}$

The nonshift worker only showed the correlation between FBG to DMF-T index ( $p=0.048)$. The DMF-T index has positive correlation with flow rate of saliva $(r=0.6, p=0.001)$. This result is opposite to Shetty et al who in her study showed that there is correlation between decreased saliva flow rate and increased DMF-T index. ${ }^{39}$ During rest, saliva flow rate is only to keep the mouth moist and lubricate the mucous membrane. Generally, greater the flow rate, better the cleansing action of saliva on tooth surface; hence, it lessens the chance of dental caries. The results suggest the lesser DMF-T status could be having similar flow rates. The conditions found in this study may be influenced by other factors not examined such as dietary patterns and the habit of maintaining oral hygiene.

A strength of this study is the evaluation of multiple factors (FBG, 2-PP BG, BMI, lifetime of working, lifetime of night working, saliva, and caries status) in the night shift worker in hospital. However, there are limitations. Sleep quality, dietary assessments, and naps were not available; data on exercise and medication compliance were not available; and light exposure at night was not measured. The night shift workers were recruited from different hospitals, and there are possibly other confounders not controlled for that could affect blood glucose control.

In summary, night shift workers are associated with higher FBG and 2-PP BG status, which can lead to diabetic development. The oral health status including flow rate of saliva, $\mathrm{pH}$ saliva, and caries is also affected and has correlation with blood glucose status. The management of night shift working and maintaining the oral health in night workers is very important to be considered as risk factor of diabetes and dental caries.

The night shift workers experience a change in time orientation due to changes in the time of working and duration of sleep. Most of night shift worker will experience the disturbance of sleep. Sleep disturbance will affect food intake, water, and metabolic processes that may play a role in the process of developing diabetes. The night shift worker received more light in the night than non-night shift worker. The increased light received will reduce the production of melanin. Research by Sadeghniiat-Haghighi et al showed that the melatonin treatment on night shift worker is able to increase the sleep quality and sleep efficiency. ${ }^{40}$ This result supports the administration of melatonin therapy to night shift workers, so it is able to regulate circadian rhythm that results in control of diabetes risk and caries risk

\section{Conclusion}

There is a circadian rhythm correlation between night shift workers and blood glucose levels, flow rate saliva, $\mathrm{pH}$ saliva, and dental caries. The results of this study can provide insight into caries control and diabetes in night shift workers. Further, there exists a possibility that maintaining good blood glucose can improve the health status of night shift workers. In addition, improving sleep quality so that the risk of diabetes and caries is also lower and melatonin therapy may also be options for night workers.

\section{Funding}

This study received funding from the RKAT Research Faculty of Dental Medicine, Universitas Airlangga in 2017.

\section{Conflict of Interest}

None declared.

\section{References}

1 Skoufi GI, Lialios GA, Papakosta S, Constantinidis TC, Galanis P, Nena E. Shift work and quality of personal, professional, and family life among health care workers in a rehabilitation center in Greece. Indian J Occup Environ Med 2017;21(3):115-120

2 Guo Y, Liu Y, Huang X, et al. The effects of shift work on sleeping quality, hypertension and diabetes in retired workers. PLoS One 2013;8(8):e71107

3 Marcheva B, Ramsey KM, Peek CB, Affinati A, Maury E, Bass J. Circadian Clocks and Metabolism. In: Kramer A, Merrow M, eds. Circandian Clocks. Handbook of Experimental Pharmacology. Vol 217. London: Springer-Verlag, Berlin Heidelberg; 2013: $127-156$

4 Shan Z, Li Y, Zong G, et al. Rotating night shift work and adherence to unhealthy lifestyle in predicting risk of type 2 diabetes: results from two large US cohorts of female nurses. BMJ 2018;363:k4641

5 Manodpitipong A, Saetung S, Nimitphong H, et al. Night-shift work is associated with poorer glycaemic control in patients with type 2 diabetes. J Sleep Res 2017;26(6):764-772

6 Buxton OM, Cain SW, O'Connor SP, et al. Adverse metabolic consequences in humans of prolonged sleep restriction combined with circadian disruption. Sci Transl Med 2012;4(129):129ra43

7 Cervino G, Terranova A, Briguglio F, et al. Diabetes: oral health related quality of life and oral alterations. BioMed Res Int 2019;2019:5907195

8 Donga E, van Dijk M, van Dijk JG, et al. A single night of partial sleep deprivation induces insulin resistance in multiple metabolic pathways in healthy subjects. J Clin Endocrinol Metab 2010;95(6):2963-2968

9 Badan Penelitian dan Pengembangan Kesehatan. Riset Kesehatan Dasar (RISKESDAS) 2013. Jakarta: Kementerian Kesehatan Republik Indonesia; 2013: 1-261

10 Badan Penelitian dan Pengembangan Kesehatan. Riset Kesehatan Dasar (RISKESDAS) 2018. Jakarta: Bada Penelitian dan Pengembangan Kesehatan, Kementerian Kesehatan Republik Indonesia; 2018 
11 Singh I, Singh P, Singh A, Singh T, Kour R. Diabetes an inducing factor for dental caries: a case control analysis in Jammu. J Int Soc Prev Community Dent 2016;6(2):125-129

12 Roth T, Nir T, Zisapel N. Prolonged release melatonin for improving sleep in totally blind subjects: a pilot placebo-controlled multicenter trial. Nat Sci. Sleep 2015;7:13-23

13 Jain K, Kaur H. Prevalence of oral lesions and measurement of salivary $\mathrm{pH}$ in the different trimesters of pregnancy. Singapore Med J 2015;56(1):53-57

14 James SM, Honn KA, Gaddameedhi S, Van Dongen HPA. Shift work: disrupted circadian rhythms and sleep-implications for health and well-being. Curr Sleep Med Rep 2017;3(2):104-112

15 Jin Y, Hur TY, Hong Y. Circadian rhythm disruption and subsequent neurological disorders in night-shift workers. J Lifestyle Med 2017;7(2):45-50

16 Chava VK, Sirisha K, Melatonin: a novel indolamine in oralhealth and disease. Int J Dent 2012; 2012:1-9

17 Bonmati-Carrion MA, Arguelles-Prieto R, Martinez-Madrid MJ, et al. Protecting the melatonin rhythm through circadian healthy light exposure. Int J Mol Sci 2014;15(12):23448-23500

18 Rana S, Mahmood S. Circadian rhythm and its role in malignancy. J Circadian Rhythms 2010;8(3):3

19 Muhammad DH, Qadir FA, Effects of night shift working on some immunological, prostate specific antigen, cortisol level and malondialdehyde in male nurses at Hawler city Effects of Night Shift Working on Some Immunological, Prostate specific antigen, Cortisol level and Malondi. AIP Conf Proc [Internet]; 2017 020035. Available at: https://doi.org/10.1063/1.5004312

20 Zelzer S, Tatzber F, Herrmann M, et al. Work intensity, lowgrade inflammation, and oxidative status: a comparison between office and slaughterhouse workers. Oxid Med Cell Longev 2018;2018:2737563

21 Hegde MN, Shetty N, Shetty P. Salivary and serum malondialdehyde levels in type 2 diabetes mellitus with dental caries. Int J Dent Res. 2015;3(2):21-23

22 Leong I. Shift work causes insulin resistance. Nat Rev Endocrinol 2018;14(9):503

23 Strohmaier S, Devore EE, Zhang Y, Schernhammer ES. A review of data of findings on night shift work and the development of DM and CVD events: a synthesis of the proposed molecular mechanisms. Curr Diab Rep 2018;18(12):132

24 Scheer FA, Hilton MF, Mantzoros CS, Shea SA. Adverse metabolic and cardiovascular consequences of circadian misalignment. Proc Natl Acad Sci U S A 2009;106(11):4453-4458

25 Siudikiene J, Machiulskiene V, Nyvad B, Tenovuo J, Nedzelskiene I, Nyvad B. Dental caries and salivary status in children with type 1 diabetes mellitus, related to the metabolic control of the disease. Eur J Oral Sci 2006;114(1):8-14

26 Latti BR, Kalburge JV, Birajdar SB, Latti RG. Evaluation of relationship between dental caries, diabetes mellitus and oral microbiota in diabetics. J Oral Maxillofac Pathol 2018;22(2):282-286

27 Vetter C, Dashti HS, Lane JM, et al. Night shift work, genetic risk, and type 2 diabetes in the UK Biobank. Diabetes Care 2018;41(4):762-769

28 Conrads G, About I. Pathophysiology of dental caries. Monogr Oral Sci 2018;27:1-10

29 Sharma A, Laurenti MC, Dalla Man C, et al. Glucose metabolism during rotational shift-work in healthcare workers. Diabetologia 2017;60(8):1483-1490

30 Ishizuka Y, Yoshino K, Takayanagi A, Sugihara N, Maki Y, Kamijyo H. Comparison of the oral health problems and behavior of male daytime-only and night-shift office workers: an Internet survey. J Occup Health 2016;58(2):155-162

31 Han DH, Khang YH, Jung-Choi K, Lim S. Association between shift work and periodontal health in a representative sample of an Asian population. Scand J Work Environ Health 2013;39(6):559-567

32 Lundgren AM, Öhrn K, Jönsson B. Do adolescents who are night owls have a higher risk of dental caries?-a case-control study. Int J Dent Hyg 2016;14(3):220-225

33 Chen Y, Lauren S, Chang BP, Shechter A. Objective food intake in night and day shift workers: a laboratory study. Clocks. Sleep 2018;1(1):42-49

34 Hoseini A, Mirzapour A, Bijani A, Shirzad A. Salivary flow rate and xerostomia in patients with type I and II diabetes mellitus. Electron Physician 2017;9(9):5244-5249

35 Seethalakshmi C, Reddy RCJ, Asifa N, Prabhu S. Correlation of salivary $\mathrm{pH}$, incidence of dental caries and periodontal status in diabetes mellitus patients: a cross-sectional study. J Clin Diagn Res 2016;10(3):ZC12-ZC14

36 Goyal D, Kaur H, Jawanda MK, Verma S, Parhar S. Salivary pH and dental caries in diabetes mellitus. Int J Oral Maxillofac Pathol. 2012;3(4):13-16

37 Ferizi L, Dragidella F, Spahiu L, Begzati A, Kotori V. The influence of type 1 diabetes mellitus on dental caries and salivary composition. Int J Dent 2018;2018:5780916

38 Puttaswamy KA, Puttabudhi JH, Raju S. Correlation between salivary glucose and blood glucose and the implications of salivary factors on the oral health status in type 2 diabetes mellitus patients. J Int Soc Prev Community Dent 2017;7(1):28-33

39 Shetty C, Hegde MN, Devadiga D. Correlation between dental caries with salivary flow, $\mathrm{pH}$, and buffering capacity in adult south Indian population: an in-vivo study research article. Int J Res Ayurveda Pharm 2013;4(2):219-223

40 Sadeghniiat-Haghighi K, Bahrami H, Aminian O, Meysami A, Khajeh-Mehrizi A. Melatonin therapy in shift workers with difficulty falling asleep: a randomized, double-blind, placebo-controlled crossover field study. Work 2016;55(1):225-230 